\title{
Glans amputation as a complication of Paraphimosis
}

\section{Yoeli Antonio Duarte Arzuaga*}

Servicio de Urología. Hospital Universitario Clínico Quirúrgico General Calixto García. La Habana, Cuba

Received: 07 May, 2020

Accepted: 14 May, 2020

Published: 15 May, 2020

*Corresponding author: Yoeli Antonio Duarte Arzuaga, Servicio de Urología. Hospital Universitario Clínico Quirúrgico General Calixto García. La Habana, Cuba, Tel: +5353453146; E-mail: duartearzuaga@gmail.com; yoeliantoniod1991@gmail.com

Keywords: Paraphimosis; Glans amputation; Prepuce https://www. peertechz.com

(D) Check for updates

\section{Abstract}

Paraphimosis is an acute situation that emerges as a complication of a congenital or aquired phimosis. This requires an urgent treatment. It occurs when the glans foreskin is stenotic, retracts behind the glans and subsequently is not brought to its normal position. As a consequence it causes strangulation of the glans and the skin of the foreskin by the stenotic ring that can evolve to edema, necrosis and amputation of the glans. We present a rare and infrequent case of amputation of the glans as a complication of paraphimosis. This is a 91-year-old male patient with a history of ischemic cardiopathy, COPD and chronic paraphimosis who, since three weeks ago, presented with pain and increased penile volume. Five days before going to the consultation her daughter notes that he had black-purple glans coloration for which she decided to apply an antiseptic solution in the area. When seeing that the clinical picture continued to worsen, they decided to go to the urological guard service of the University Hospital "General Calixto Garcia". Physical examination revealed a necrotic glans without vitality and amputation. The proximal end to the healthy preputial ring without signs of ischemia or sepsis. The case constitutes a urological urgency that in most cases is resolved by simple manual reduction. Necrosis and amputation of the glans as a complication of paraphimosis is extremely rare. To date, few cases are described in the literature. The circumcision must be performed in every patient who has presented paraphimosis.

\section{Introduction}

Paraphimosis is an acute situation that arises as a complication of a congenital or acquired phimosis and requires urgent treatment. It occurs when the stenotic foreskin retracts behind the glans and subsequently is not brought to its normal position, as a result edema appears on the skin of the foreskin and strangulation of the glans that can progress to necrosis. We present a rare case of glans amputation as a complication of paraphimosis [1].

\section{Case presentation}

A 91-year-old male patient with a personal pathological history of ischemic heart disease, COPD, and recurrent paraphimosis, who had pain and increased penile volume for about three weeks, despite which he did not go to the doctor. Her daughter notes that her father has black-purple coloration of the glans, five days before consulting for which he decided to apply antiseptic solution in the area without prior medical prescription. Before the worsening of the picture they decide to go to the Service of Urology Guard of the Calixto Garcia Teaching Hospital.
Physical examination revealed a gland with a necrotic appearance without vitality, with partial amputation and a healthy preputial ring without signs of ischemia or sepsis.

Urgent hemochemistry tests were performed, which were negative.

It was decided to perform emergency surgery to complete the amputation of the glans and reconstruct the urethra. Local anesthetic was applied at the base of the penis and around the neomeate. Antibiotic treatment was started. The patient evolved favorably and was discharged at 48 hours with an urethral catheter that was removed after 10 days. (Figures 1-3).

\section{Discussion}

Paraphimosis is an urological emergency that usually occurs in children and adults who have not been circumcised. It arises when the stenotic foreskin retracts behind the glans and is not brought back to its normal position. As a result, the stenotic ring compresses the glans and the skin of the prepuce. Subsequently, the venous and lymphatic drainage is obstructed, which causes edema of the glans that increases its size, producing a greater disproportion between the size of the glans and the preputial 


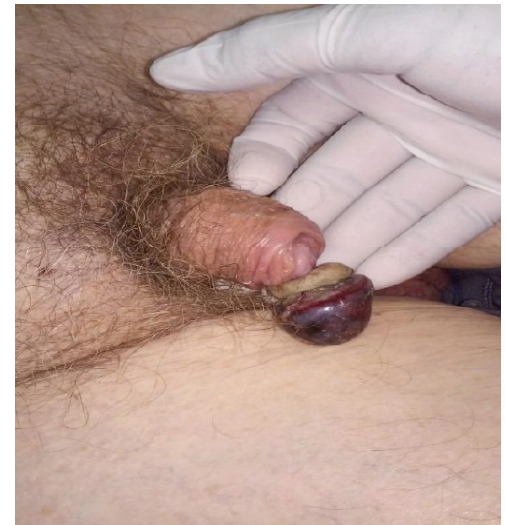

Figure 1: Amputated glans.

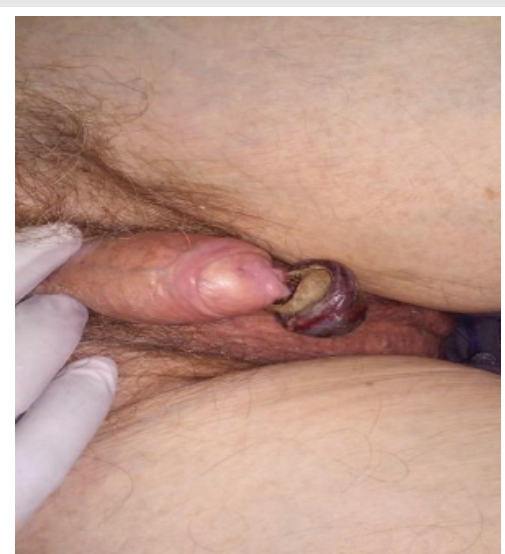

Figure 2: Necrotic gland

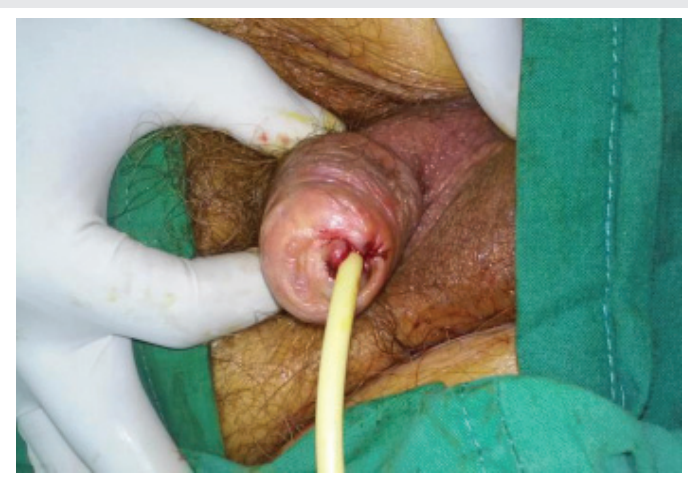

Figure 3: Urethral reconstruction.

ring. Simultaneously the circulation of the foreskin becomes difficult, which is also dematized. If the condition is not treated properly, it can cause infection and vascularization compromise that can lead to gangrene of the glans [1].
The most frequent cause of paraphimosis is observed when an urethro-vesical catheter is placed and the prepuce is forgotten in its proper place [2].

There are other causes, such as retraction of the foreskin when the penis is cleansed, during the physical examination of the penis or other instrumentation or after the sexual act if the foreskin is not repositioned in its normal position [3].

The diagnosis is made easily by inspection. An edematous glans is found and increased in size with respect to the penis. With a thick edematous foreskin that is separated abruptly from the rest of the penis by a ring of fibrous constriction. Depending on the time of evolution, ulcerations, changes in coloration or necrosis of the glans can be found.

For its treatment, the manual reduction of the foreskin, placement of cold water bags, the injection of hyaluronidase, osmotic methods, multiple punctures and aspiration of the edematous area or section of the constrictor ring under local anesthesia are described $[3,4]$.

The necrosis and self-amputation of the glans as a complication of paraphimosis is extremely rare and even more so now, if we take into account the access of the population to medical services. In the bibliography consulted, only one similar case was found published by Hollowood, et al. [5], which required partial amputation by chronic non-reduced paraphimosis that produced a complete section of the urethra.

\section{Conclusion}

Paraphimosis is an urological urgency that must be resolved as soon as it is diagnosed and in most cases this is achieved with simple manual reduction. Necrosis and amputation of the glans as a complication of paraphimosis is extremely rare.

\section{References}

1. Moncada Iribarren I, Rodríguez Fernández E, Leal Hernández F, Sánchez Carreras Aladrén F, et al. (1996) Urgencias Urológicas. Madrid: Asociacion española de Urologia 22. Link: https://bit.ly/2WU9H6r

2. Choe JM (2000) Paraphiposis. Current treatment options. Am Fam Physician 62: 2623-2626. Link: https://bit.ly/2SZLOcM

3. Bragg BN, Leslie SW (2018) Paraphimosis. In: StatPearls. Treasure Island (FL): StatPearls. Link: https://bit.ly/3ctguL9

4. Raman SR, Kate V, Ananthakrishnan N (2008) Coital paraphimosis causing penile necrosis. Emerg Med J 25: 454. Link: https://bit.ly/2WsS6DH

5. Palmisano F, Gadda F, Spinelli MG, Montanari E (2018) Glans penis necrosis following paraphimosis: A rare case with brief literature review. Urol Case Rep 16: 57-58. Link: https://bit.ly/2Z5GhF8 